\title{
Communications
}

\section{Examen de spécialiste \\ Examen de spécialiste en vue de l'obtention du titre de spécialiste en néphrologie}

Date: les 26 et 27 mai 2021

Lieu: Berne

\section{Délai d’inscription: le 5 avril 2021}

Vous trouverez de plus amples informations sur le site web de l'ISFM www.siwf.ch $\rightarrow$ formation postgraduée $\rightarrow$ Titres de spécialiste et formations approfondies $\rightarrow$ néphrologie

Obtention a posteriori de la formation approfondie en "gynécologieobstétrique opératoire»

La nouvelle formation approfondie en "gynécologie-obstétrique opératoire» a été lancée par l'ISFM le 1.7.2008. Comme dans les autres domaines, la formation postgraduée de médecin spécialiste en gynécologie et obstétrique a été réduite à un curriculum de 5 ans, d'approche conservatrice, tout en étant en parallèle enrichie de formations approfondies opératoires.

Les médecins spécialistes en gynécologie et obstétrique qui avaient obtenu leur titre de spécialiste selon l'ancien programme de formation postgraduée du 1.1.2002 ont profité de dispositions transitoires généreuses: ils ont obtenu le nouveau titre sans aucune autre condition. La demande devait cependant être déposée dans un délai de 10 ans, à savoir jusqu'au 30.6.2018 au plus tard. Plusieurs consœurs et confrères ont raté ce délai et ne peuvent à présent plus faire valoir aucune formation approfondie opératoire.

Sur demande de la Société suisse de Gynécologie et d'Obstétrique (SSGO), l'ISFM offre désormais la possibilité de valider la formation approfondie malgré l'expiration du délai.

L'inscription à l'examen doit intervenir au plus tard le 31.12.2021. Passé ce délai, la formation approfondie devra être obtenue selon les dispositions ordinaires.

Pour plus de détails, voir www.sggg.ch
Kongress des Schweizerischen Verbands Medizinischer PraxisFachpersonen SVA kann stattfinden

Der SVA kann seinen 50. Kongress zum Thema «Meilensteine» vom 6 . bis zum 8. November 2020 in Davos durchführen. Grundlage für den positiven Entscheid bildet ein rigoroses Schutzkonzept. Der SVA feiert sein 40-jähriges Bestehen in seiner heutigen Verbandsform und die Durchführung seines 50. Kongresses in Folge.

Der diesjährige Kongress möchte die Meilensteine rund um den Beruf Revue passieren lassen. Für den Besuch der gesamten Tagung hat die SGAIM 3 Kernfortbildungscredits AIM akkreditiert. Beim Besuch von einzelnen Kongresstagen oder -halbtagen werden diese anteilmässig testiert.

Das detaillierte Programm, wie weitere Informationen zur Anmeldung, finden Sie unter www.sva.ch $\rightarrow$ Davoser Kongress

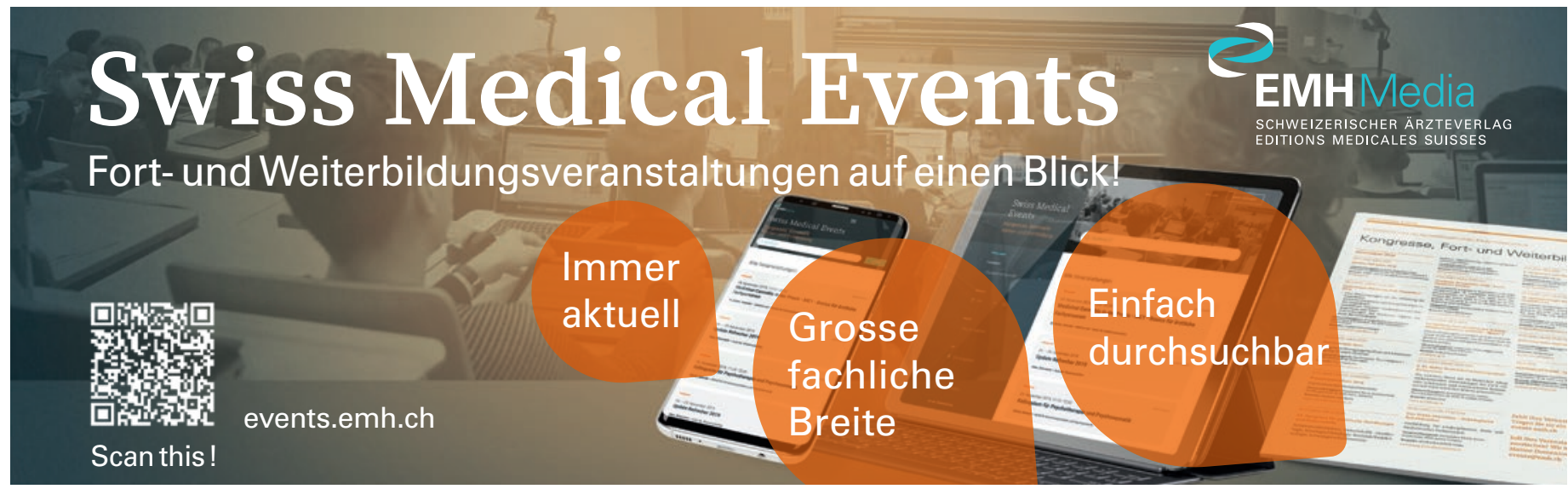

